\title{
Development of a rapid assay to detect the jellyfish Cyanea nozakii using a loop-mediated isothermal amplification method
}

\author{
Zhongyuan Liu ${ }^{1,2}$, Zhijun Dong ${ }^{1}$, and Dongyan Liu ${ }^{1}$ \\ ${ }^{1}$ Key Laboratory of Coastal Zone Environmental Processes and Ecological Remediation, Yantai Institute of Coastal Zone Research, Chinese Academy \\ of Sciences, Yantai, Shandong, PR China and ${ }^{2}$ University of the Chinese Academy of Sciences, Beijing, PR China
}

\begin{abstract}
Blooms of the harmful jellyfish Cyanea nozakii, which are a severe nuisance to fisheries and tourisms, frequently occur in the northern East China Sea, Yellow Sea, and Bohai Sea. To provide early warning of this species, a simple and effective molecular method for identifying C. nozakii was developed using the loop-mediated isothermal amplification method (LAMP). The LAMP assay is highly specific and uses a set of four primers that target six different regions on the mitochondrial cytochrome $\mathrm{c}$ oxidase subunit I (COI) gene of $\mathrm{C}$. nozakii. The amplification conditions, including the dNTP and betaine concentrations, the inner primer to outer primer concentration ratio, reaction time and temperature, were optimized. The LAMP assay amplified DNA extracted from tissue samples of $C$. nozakii but did not amplify DNA from other common scyphozoans and hydrozoans collected in the same region. In addition, the LAMP assay was more sensitive than conventional PCR. Therefore, the established LAMP assay is a sensitive, specific, fast, and easily performed method for detection of $C$. nozakii at different stages in their life cycle.
\end{abstract}

\author{
Keywords \\ Cyanea nozakii, cytochrome c oxidase \\ subunit I, jellyfish blooms, LAMP, \\ mitochondrial DNA
}

\section{History}

Received 17 January 2015

Revised 12 February 2015

Accepted 15 February 2015

Published online 16 March 2015

\section{Introduction}

The harmful jellyfish Cyanea nozakii is distributed widely in the northern East China Sea, Yellow Sea, and Bohai Sea (Hong \& Lin, 2010). Since the late 1990s, blooms of C. nozakii frequently occurred in the fishing grounds (e.g. Lvsi, Dasha, Yangtze Estuary, and Liaodong Bay) (Chen et al., 2007; Dong et al., 2010; Ge \& He, 2004; Xian et al., 2005). These has caused serious damages to local fisheries, including splitting and ruining fishing nets, preying on and killing juvenile fish, crabs and mollusks, and producing toxins that are dangerous to people and marine animals (Feng et al., 2010; Zhong et al., 2003; Zhou \& Huang, 1956). For example, in the summer of 2004, the bloom of C. nozakii in Liaodong Bay in the Bohai Sea caused a nearly $80 \%$ decline in the edible jellyfish Rhopilema esculentum and economic losses of approximately US $\$ 70$ million (Ge \& He, 2004).

The life cycle of $C$. nozakii is highly complex and diverse, with combinations of planulae, benthic polyps, ephyra, and pelagic medusa (Dong et al., 2006; Lucas, 2012). Compared with pelagic medusa (Dong et al., 2005; Lu et al., 2003; Wang et al., 2014; Zhong et al., 2003; Zhou \& Huang, 1956), limited work has considered the larval and juvenile stages of $C$. nozakii due to their small and cryptic nature (Dong et al., 2006). Currently, adult Cyanea species are usually identified through traditional morphological identification, which is time consuming and requires specialized taxonomic knowledge and experience (Dong et al., 2005). However, it is difficult to identify C. nozakii in their larval and juvenile stages. For example, the planulae of $C$. nozakii vary

Correspondence: Dr. Zhijun Dong, Yantai Institute of Coastal Zone Research, Chinese Academy of Sciences, Yantai, Shandong 264003, PR China. Tel/Fax: +86 535 2109270. E-mail: zjdong@yic.ac.cn from slipper-shaped to irregularly oval with $90-180 \mu \mathrm{m}$ in length and 60-95 $\mu \mathrm{m}$ in width, and the benthic scyphistomae vary in size and shape (Dong et al., 2006). Molecular data can provide useful information for species identification of $C$. nozakii at different stages of their life cycle, because the genome remains the same at different life stages (Miranda et al., 2010).

As an alternative to morphological identification, molecular techniques have been used to identify the medusozoa (Bayaha \& Graham, 2009; Bucklin et al., 2011; Daryanabard \& Dawson, 2008; Ki et al., 2008, 2010; Laakmann \& Holst, 2014; Ortman et al. 2010). In these studies, mitochondrial cytochrome c oxidase subunit I (COI) gene was widely used as the DNA barcode for marine Metazoa and Medusozoa (Bucklin et al., 2011; Daryanabard \& Dawson, 2008; Ki et al., 2008; Laakmann \& Holst, 2014; Ortman et al. 2010). Various detection methods using genetic markers have been developed to detect jellyfish, including DNA sequencing (Daryanabard \& Dawson, 2008; Ki et al., 2008; Laakmann \& Holst, 2014), real-time PCR (Bayaha \& Graham, 2009) and DNA microarray (Ki et al., 2010). These molecular techniques are highly sensitive, specific, and efficient for detecting harmful jellyfish at different stages of their life cycle. However, these techniques also require specialized and expensive instruments, which may preclude practical application of these methods. Therefore, a simple and effective method for identifying and detecting the harmful jellyfish $C$. nozakii needs to be developed.

Recently, a novel Loop-mediated isothermal amplification (LAMP) diagnostic method was developed and performed by the Bst DNA polymerase under isothermal conditions (Notomi et al., 2000). The LAMP assay presents some advantages over traditional PCR-based methods. For example, the LAMP reaction does not require expensive laboratory equipment such as a 
thermal cycler; the result is obtained within $1 \mathrm{~h}$ or less; the result shows specificity because $4-6$ primers are required that hybridize against 6-8 distinct sequences in the target DNA; and the amplified products are visualized simply through an increase in turbidity or change in color detected through the use of an intercalating fluorescent dye such as SYBR Green I (Mori et al., 2001; Notomi et al., 2000). LAMP-based assays have been used for rapid and sensitive detection of microorganisms and harmful microalgae (Chen \& Cui, 2009; Chen et al., 2013; Nagai et al., 2012; Picon-Camacho et al., 2013; Woźniakowski et al., 2012; Zhang et al., 2013, 2014). The aim of the present study was to develop a sensitive, specific, and cost-effective LAMP-based approach for the detection of the harmful jellyfish $C$. nozakii.

\section{Materials and methods}

\section{Sample collection}

A total of 22 C. nozakii specimens used in this study were collected in the Jiaozhou Bay during a local jellyfish blooming time in 2013. To test the specificity of the method, 15 species of scyphozoan and hydrozoan jellyfish that are commonly distributed in the Yellow and Bohai Seas were also collected, including Nemopilema nomurai, Rhopilema esculentum, Aurelia aureta, Sarsia tubulosa, Clytia gracilis, C. hemisphaerica, C. xiamenensis, Corymorpha bigelowi, Eirene ceylonensis, Malagazzia taeniogonia, Parisotoma notabilis, Sugiura chengshanense, Turritopsis nutricula, Obelia sp., and Rathkea octopunctata (Tables 1 and 4). Medusae tissue extracted from the bell margin or oral arms was preserved in 95\% ethanol for DNA extraction.

\section{DNA extraction, PCR, and sequencing}

The total genomic DNA was extracted using a TIANamp Marine Animals DNA Kit (Tiangen, Beijing, China). Approximately $50 \mathrm{mg}$ tissues of each individual were weighed and used for DNA extraction. The concentration of the extracted genomic DNA was determined and adjusted with a NanoDrop 2000c Spectrophotometer (Thermo Fisher Scientific, Waltham, MA). DNA was dissolved in $100 \mu \mathrm{L}$ of TE buffer and stored at $-20^{\circ} \mathrm{C}$ until use.

Table 1. Information sources on the mitochondrial cytochrome $\mathrm{c}$ oxidase subunit I (COI) gene of Cyanea species used for LAMP primer design for Cyanea nozakii.

\begin{tabular}{llll}
\hline No. & Species & Isolation source & $\begin{array}{l}\text { Accession } \\
\text { number }\end{array}$ \\
\hline 1 & Cyanea nozakii & Jiaozhou Bay, China & This study \\
2 & C. purpurea & Yangtze River Estuary, China & JQ353737 \\
3 & C. capillata & Baltic Sea & JX995346 \\
4 & C. rosea & Merimbula Lake, Australia & AY902922 \\
5 & C. lamarckii & North Sea & JX995362 \\
6 & C.annaskala & Port Phillip Bay, Australia & AY902923 \\
\hline
\end{tabular}

The mitochondrial COI fragments from C. nozakii were amplified using the universal primers LCO1490 and HCO2198 under previously described PCR conditions (Folmer et al., 1994). The PCR reactions were carried out in a volume of $50 \mu \mathrm{L}$ that consisted of 50-100 ng genomic DNA, $1 \times$ PCR buffer, $1.5 \mathrm{mM}$ $\mathrm{MgCl}_{2}, 0.2 \mathrm{mM}$ dNTPs, $0.25 \mathrm{mM}$ primers, and $2.5 \mathrm{U}$ Taq DNA polymerase (Tiangen, Beijing, China). The temperature profile was defined as follows: $94^{\circ} \mathrm{C}$ for $3 \mathrm{~min} ; 30$ cycles of denaturation at $94{ }^{\circ} \mathrm{C}$ for $30 \mathrm{~s}$, annealing at $54.5^{\circ} \mathrm{C}$ for $30 \mathrm{~s}$, and extension at $72{ }^{\circ} \mathrm{C}$ for $60 \mathrm{~s}$; followed by a final extension at $72{ }^{\circ} \mathrm{C}$ for $5 \mathrm{~min}$. The PCR products were analyzed by $1 \%$ agarose gel electrophoresis according to the standard method. PCR-amplified DNA fragments were purified and sequenced with an ABI 3730 automatic DNA sequencer at Sangon Biotech Co., Ltd (Shanghai, China) using the same primers described above. All PCR products were sequenced in both directions to obtain accurate sequences.

\section{Design and synthesis of the primers for LAMP}

Three sets of LAMP primers targeting the mitochondrial cytochrome c oxidase subunit I gene (COI) of $C$. nozakii were designed based on the gene sequences obtained from this study (Table 1) using the program PrimerExplorer V4 (http://primerexplorer.jp/elamp4.0.0/index.html). Then, a BLAST search was used to confirm the specificity of the designed primers against a broad range of organisms. $\mathrm{CN}-\mathrm{FIP}$ and $\mathrm{CN}-\mathrm{BIP}$ were inner primers, and $\mathrm{CN}-\mathrm{F} 3$ and $\mathrm{CN}-\mathrm{B} 3$ were out primers (Table 2). Primers were synthesized by Sangon Biotech Co., Ltd (Shanghai, China).

\section{Optimization of LAMP conditions}

The LAMP reaction was conducted following the method described in Notomi et al. (2000). Various parameters, including the concentrations of dNTP and betaine, the concentration ratio of inner primer to outer primer, the reaction time, and the temperature, were tested to optimize the LAMP reactions. LAMP was performed using $0-0.8 \mathrm{mM}$ dNTPs and $0.2-1.4 \mathrm{M}$ betaine, and the ratios of inner primer concentration to outer primer concentration ranged from 1:1 to 16:1; the other conditions were unchanged. The reaction temperature was tested at 57, 59, 61,63 , and $65^{\circ} \mathrm{C}$ at a predetermined time of $60 \mathrm{~min}$ followed by $80^{\circ} \mathrm{C}$ for $5 \mathrm{~min}$ for the termination. To determine the optimum incubation time for the LAMP assay, the mixture was tested at $62{ }^{\circ} \mathrm{C}$ for $10,20,30,40,50,60,70$, and $80 \mathrm{~min}$. The optimized LAMP conditions are summarized in Table 3 and were used in subsequent studies. The LAMP reactions were carried out in a volume of $25 \mu \mathrm{L}$ that consisted of $1.6 \mu \mathrm{M}$ each of inner primer, $0.2 \mu \mathrm{M}$ each of outer primer, $0.6 \mathrm{M}$ betaine, $0.4 \mathrm{mM}$ dNTPs, $1 \times$ thermopol buffer $(20 \mathrm{mM}$ Tris- $\mathrm{HCl}, 10 \mathrm{mM} \mathrm{KCl}, 10 \mathrm{mM}$ $\left(\mathrm{NH}_{4}\right)_{2} \mathrm{SO}_{4}, 6 \mathrm{mM} \mathrm{MgSO} 4,0.1 \%$ Triton X-100), $8 \mathrm{U}$ Bst DNA polymerase large fragment (New England Biolabs Inc., Ipswich, MA), and specified amounts of DNA. The mixture was incubated at $63{ }^{\circ} \mathrm{C}$ for $30 \mathrm{~min}$ and then heated at $80^{\circ} \mathrm{C}$ for $10 \mathrm{~min}$ to terminate the reaction.

Table 2. Primer sequences for LAMP detection in Cyanea nozakii. Mitochondrial cytochrome c oxidase subunit I (COI) gene was used for the LAMP detection.

\begin{tabular}{llc}
$\begin{array}{l}\text { Primer } \\
\text { name }\end{array}$ & Primer sequence & Length \\
\hline CN-F3 & ATGCCTGTTCTTATAGGAGG & 20 \\
CN-B3 & CCATGTCTACAGATCCTCC & 19 \\
CN-FIP & TGTTAAGTCTGGGGAAAGCCATATTTGGTAACTGACTTATACCTTTG & 47 \\
CN-BIP & ATCAGCTTTAATAGAACAAGGTGCATGAATAGATGCTAAAGTGGGATA & 48 \\
\hline
\end{tabular}


The LAMP products were analyzed by $1 \%$ agarose gel electrophoresis and photographed with a Gel Doc ${ }^{\mathrm{TM}}$ $\mathrm{XR}+$ imaging system transilluminator (Bio-Rad, Hercules, CA). In addition, the result could be directly observed through the white magnesium pyrophosphate precipitate or the green color generated by adding $1 \%$ SYBR Green I.

\section{Sensitivity of the LAMP assay}

To determine the sensitivity of the LAMP assay, 10-fold serial dilutions (from $100 \mathrm{ng} \mu \mathrm{L}^{-1}$ to $10^{-5} \mathrm{ng} \mu \mathrm{L}^{-1}$ ) of DNA extracted from $C$. nozakii were used as templates for LAMP under the optimized conditions. In addition, a COI PCR test was performed as described in DNA extraction, PCR, and sequencing section. Products obtained were analyzed by $1 \%$ agarose gel

Table 3. Optimized LAMP conditions, including reaction time and temperature, the dNTP and betaine concentrations, and the inner primer to outer primer concentration ratio.

\begin{tabular}{lcccc}
\hline $\begin{array}{l}\text { Reaction } \\
\text { time }\end{array}$ & $\begin{array}{c}\text { Reaction } \\
\text { temperature }\end{array}$ & $\begin{array}{c}\mathrm{dNTP} \\
\text { concentrations }\end{array}$ & $\begin{array}{c}\text { Betaine } \\
\text { concentrations }\end{array}$ & $\begin{array}{c}\text { Ratio of inner } \\
\text { primer to } \\
\text { outer primer }\end{array}$ \\
\hline $30 \mathrm{~min}$ & $63^{\circ} \mathrm{C}$ & $0.4 \mathrm{mM}$ & $0.6 \mathrm{M}$ & $8: 1$ \\
\hline
\end{tabular}

electrophoresis and visualized with a Gel $\operatorname{Doc}^{\mathrm{TM}} \mathrm{XR}+$ imaging system transilluminator (Bio-Rad, Hercules, CA).

\section{Species-specific detection by LAMP}

To confirm the species-specific detection of $C$. nozakii by the LAMP method, amplification of the target and non-target species was conducted (Table 4). In the case of $C$. nozakii, 22 individuals of $C$. nozakii were tested for amplification of the target species, and 15 species of non-target species were also tested for amplification. DNA concentrations of all tested samples were adjusted to $10-50 \mathrm{ng} \mu \mathrm{L}^{-1}$.

\section{Results and discussion}

Three primer sets specific to $\mathrm{mt}$ COI were created using the automatic search function of Primer Explorer V4. Then, the best primer sets were selected through further BLAST search against a wide range of organisms. Finally, one specific primer set for the target DNA was selected for primer screening using LAMP (Table 2). The LAMP assay was carried out using C. nozakii DNA to establish the optimal conditions. The results of all the tests are shown in Figure 1. The optimized LAMP conditions are summarized in Table 3. The results indicated that the target gene could not be amplified when the concentration of betaine was higher than $1.2 \mathrm{M}$, and optimal amplification was achieved at

Table 4. Species-specific detection of Cyanea nozakii by the LAMP method.

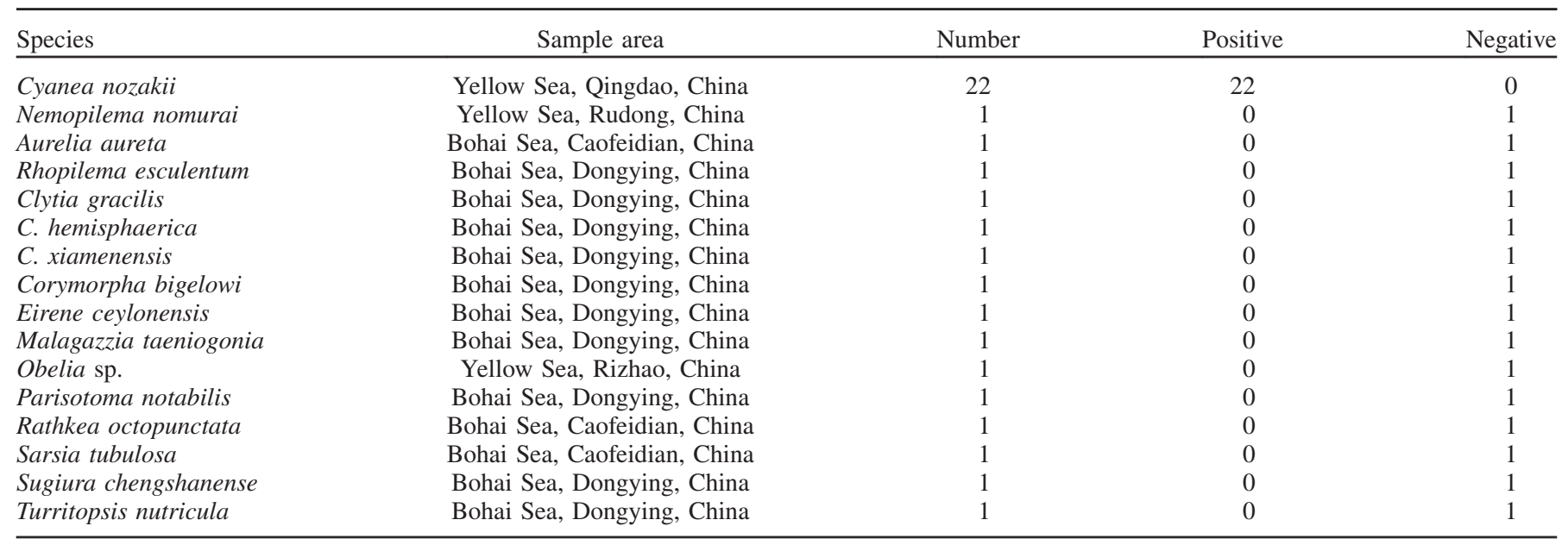

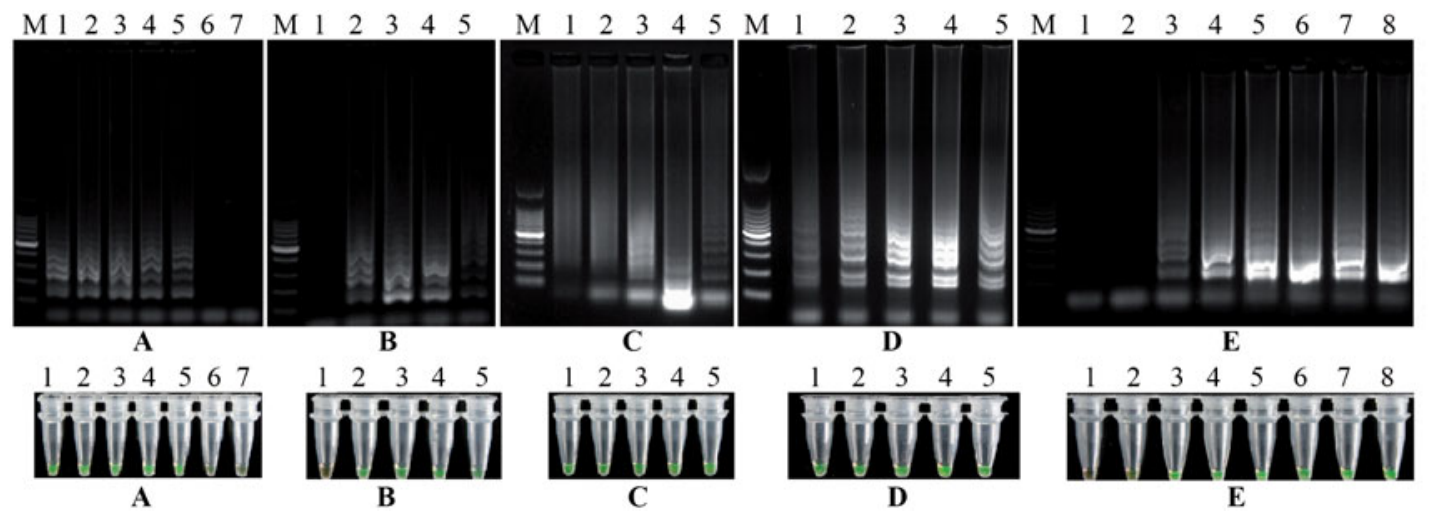

Figure 1. Optimization of LAMP conditions, observed by electrophoresis analysis and visual detection, including the betaine (A) and dNTP (B) concentrations, the inner primer to outer primer concentration ratio (C), temperature (D), and reaction time (E). M: 100 bp DNA ladder. (A) L1-7: the betaine concentration is $0.2,0.4,0.6,0.8,1.0,1.2$, and $1.4 \mathrm{M}$; (B) L1-5: the dNTP concentration is $0,0.2,0.4,0.6$, and $0.8 \mathrm{M}$; $(\mathrm{C}) \mathrm{L} 1-5$ : the concentration ratio of inner primer to outer primer is $1: 1,2: 1,4: 1,8: 1$, and $16: 1$; (D) L1-5: the reaction temperature is $57,59,61,63$, and $65^{\circ} \mathrm{C}$; (E) L1-5: the reaction time is $10,20,30,40,50,60,70$, and 80 min. 
(A)

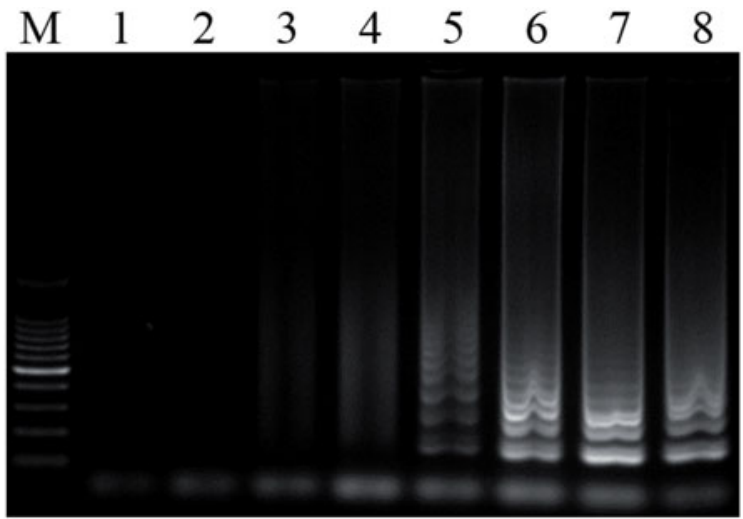

(B)

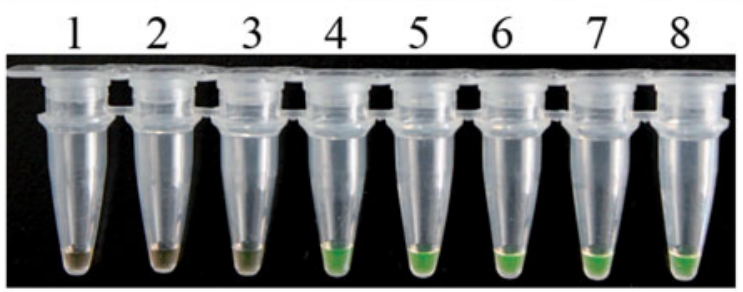

(C)



Figure 2. Comparison of the sensitivities of LAMP (A and B) and PCR (C). Lane M:100 bp DNA ladder; lanes 1-8: 10-fold dilutions of DNA corresponding to $10^{-5} \mathrm{ng} \mu \mathrm{L}^{-1}, 10^{-4} \mathrm{ng} \mu \mathrm{L}^{-1}, 10^{-3} \mathrm{ng} \mu \mathrm{L}^{-1}, 10^{-2} \mathrm{ng}$ $\mu \mathrm{L}^{-1}, 10^{-1} \mathrm{ng} \mu \mathrm{L}^{-1}, 1 \mathrm{ng} \mu \mathrm{L}^{-1}, 10 \mathrm{ng} \mu \mathrm{L}^{-1}$, and $100 \mathrm{ng} \mu \mathrm{L}^{-1}$.
0.6 M (Figure 1A). Previous study suggested that betaine improved the DNA amplification by reducing the formation of secondary structure caused by GC-rich regions (Henke et al., 1997). However, the mt COI of C. nozakii in our study have a low GC content (34\%). Lower betaine concentration may result in elevated LAMP amplification efficiency when amplifying nonGC-rich target sequences (Chen et al., 2011). The band appeared to be more clear with the addition of $0.4 \mathrm{mM}$ dNTP than with other concentrations (Figure 1B). A more distinct pattern was apparent when the primer ratio was 1:8 (Figure 1C). As shown in Figure 1(D), there was amplification of the LAMP product between $57^{\circ} \mathrm{C}$ and $65^{\circ} \mathrm{C}$, and the clearer bands were observed at $63^{\circ} \mathrm{C}$, suggesting that as the optimal temperature for the assay. No amplification was observed after incubation for 10 and $20 \mathrm{~min}$ (Figure 1E). The first LAMP products appeared after $30 \mathrm{~min}$, suggesting that the minimum reaction time for the LAMP assay to detect $C$. nozakii DNA was $30 \mathrm{~min}$. Based on the above results, the optimal conditions for the LAMP assay of $C$. nozakii were determined to be $63{ }^{\circ} \mathrm{C}$ for $30 \mathrm{~min}$ with $0.6 \mathrm{M}$ betaine, $0.4 \mathrm{mM}$ dNTPs, $0.2 \mathrm{mM}$ each of outer primer, and $1.6 \mathrm{mM}$ each of inner primer.

The detection limit for DNA extracts from $C$. nozakii in the LAMP reaction was tested. The present results showed that $0.1 \mathrm{ng}$ of DNA extracted from $C$. nozakii was observed by agarose gel electrophoresis for LAMP (Figure 2A). Comparatively, a positive result was only observed when the DNA extract was $10 \mathrm{ng}$ for PCR (Figure 2B). Therefore, the LAMP assay displayed a higher amplification efficiency, and LAMP was 100-fold more sensitive than PCR. The presented results are consistent with previous studies (Chen et al., 2013; Notomi et al., 2000; Picon-Camacho et al., 2013; Zhang et al., 2013). For example, Notomi et al. (2000) first demonstrated that the sensitivity of LAMP is much higher than conventional PCR. Chen et al. (2013) showed that the LAMP-based assay for detecting Prorocentrum donghaiense was more sensitive than PCR. Picon-Camacho et al. (2013) also confirmed that the LAMP assay for Amyloodinium ocellatum was exceptionally higher than conventional PCR. Zhang et al. (2013) found that the sensitivity of the LAMP method for detecting Prorocentrum was a minimum of 10 times greater than for traditional PCR.

Primer set design is critical for the success of LAMP assays in detecting $C$. nozakii because samples may consist of a wide range of jellyfish species (e.g. hydrozoa and Scyphozoa). The

(A)

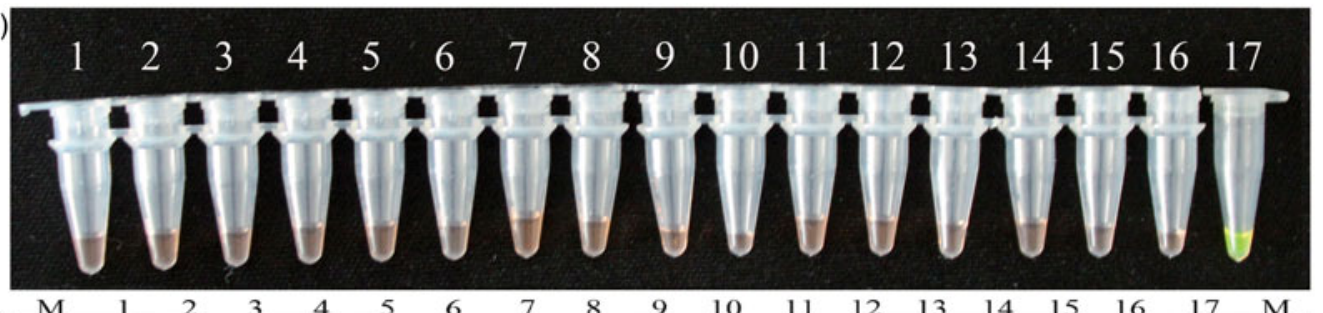

(B)

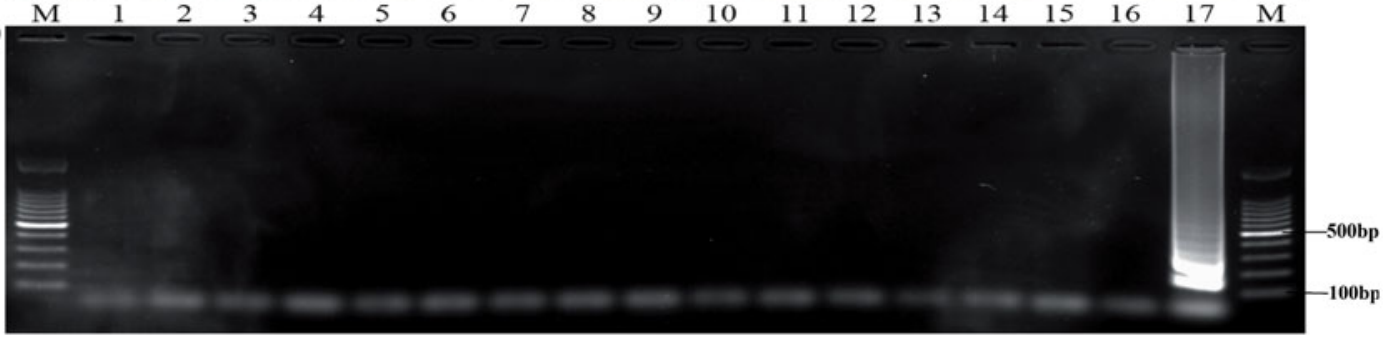

Figure 3. Specific detection of Cyanea nozakii by the LAMP method. (A) Amplification of LAMP products dyed with SYBR Green I was visually detected by examining color changes with the naked eye: green indicates a positive result and orange indicates a negative result. (B) Agarose gel electrophoresis. Lane M: 100 bp DNA ladder; lane 1: Clytia gracilis; L2, Clytia hemisphaerica; L3, Clytia xiamenensis; L4, Corymorpha bigelowi; L5, Eirene ceylonensis; L6, Malagazzia taeniogonia; L7, Parisotoma notabilis; L8, Sugiura chengshanense; L9, Turritopsis nutricula; L10, Obelia sp.; L11, Rathkea octopunctata; L12, Sarsia tubulosa; L13, Aurelia aureta; L14, Nemopilema nomurai; L15, Rhopilema esculentum; L16, negative control; L17, Cyanea nozakii. 
specificity of primers were further determined by experimental analysis. All 22 individuals of $C$. nozakii produced positive results, while the other non-target scyphozoan and hydrozoan species produced negative results, indicating that the LAMP assay was highly specific to $C$. nozakii (Figure 3). The LAMP-based assay was highly specific for the target sequence because six independent sequences recognize the target sequence in the initial stage, and four independent sequences amplify the target sequence in the later stage of the reaction (Mori et al., 2001; Nagamine et al., 2002; Notomi et al., 2000).

In summary, the LAMP method described here is a sensitive, specific, fast, and easily performed method for the detection of the harmful jellyfish $C$. nozakii. First, the LAMP assay was performed with only a water bath or heat block for incubation under isothermal conditions. Second, the LAMP reaction can be completed in $30 \mathrm{~min}$, which is suitable for analysis of a large number of samples. Third, the LAMP assay was more sensitive and specific than traditional PCR. Fourth, the amplified products are visualized simply through an increase in turbidity (Mori et al., 2001; Notomi et al., 2000) or change in color through the use of an intercalating fluorescent dye such as SYBR Green I or Calcein (Mori et al., 2001). Since the late 1990s, harmful C. nozakii jellyfish blooms have been frequently observed (reviewed in Dong et al., 2010). The monitoring of $C$. nozakii, especially at the larval and juvenile stages, may provide early warning of this species to avoid loss for fisheries and tourism. Therefore, the LAMP assay developed in the present study will be valuable in the detection of $C$. nozakii at different life cycle stages.

\section{Acknowledgements}

The authors thank Youfang Sun, Qianwen Qu, and Guoxiu Zhang for their assistance in the field investigation and experiment.

\section{Declaration of interest}

The authors report that they have no conflicts of interest. This work was supported by grants from the National Natural Science Foundation of China (No. 41206086), the Strategic Priority Research Program of Chinese Academy of Sciences (Nos. XDA05130703 and XDA11020405), and the Research Encouragement Foundation of Excellent Midlife-Youth Scientists of Shandong Province (No. BS2011HZ023).

\section{References}

Bayha KM, Graham WM. (2009). A new Taqman $($ PCR-based method for the detection and identification of scyphozoan jellyfish polyps. Hydrobiologia 616:217-28.

Bucklin A, Steinke D, Blanco-Bercial L. (2011). DNA barcoding of marine metazoa. Annu Rev Mar Sci 3:471-508.

Chen CM, Cui SJ. (2009). Detection of porcine parvovirus by loopmediated isothermal amplification. J Virol Methods 155:122-5.

Chen G, Ma C, Zhang C, Zhou J, Wang Y, Wang G, Lu DD. (2013). A rapid and sensitive method for field detection of Prorocentrum donghaiense using reverse transcription-coupled loop-mediated isothermal amplification. Harmful Algae 29:31-9.

Chen S, Wang F, Beaulieu JC, Stein RE, Ge B. (2011). Rapid detection of viable salmonellae in produce by coupling propidium monoazide with loop-mediated isothermal amplification. Appl Environ Microbiol 77:4008-16.

Chen W, Bo Z, Zhou W, Xue L. (2007). Investigation of the familiar jellyfish species in Zhejiang Sea area and their influence on fishery in flourishing year. J Zhejiang Ocean Univ (Nat Sci) 26:266-71.

Daryanabard R, Dawson MN. (2008). Jellyfish blooms: Crambionella orsini (Scyphozoa: Rhizostomeae) in the Gulf of Oman, Iran, 20022003. J Mar Biol Assoc UK 88:477-83.

Dong J, Liu C, Li W, Yu H, Wang B, Wang Y. (2005). The morphology and structure of jellyfish (Cyanea nozakii Kishinouye). Fish Sci 24:22-3.

Dong J, Wang B, Liu C. (2006). Morphology of Cyanea nozakii in different developmental stages. J Fish China 30:761-6.

Dong Z, Liu D, Keesing JK. (2010). Jellyfish blooms in China: Dominant species, causes and consequences. Mar Pollut Bull 60:954-63.
Feng J, Yu H, Li C, Xing R, Liu S, Wang L, Li P. (2010). Isolation and characterization of lethal proteins in nematocyst venom of the jellyfish Cyanea nozakii Kishinouye. Toxicon 55:118-25.

Folmer O, Black M, Hoeh W, Lutz R, Vrijenhoek R. (1994). DNA primers for amplification of mitochondrial cytochrome $\mathrm{c}$ oxidase subunit I from diverse metazoan invertebrates. Mol Mar Biol Biotech 3:294-9.

Ge L, He D. (2004). Bloom of Cynea nozakii in Liaodong Bay caused decline in the edible jellyfish Rhopilema esculentum. China Fish $23-$ 25. (in Chinese).

Henke W, Herdel K, Jung K, Schnorr D, Loening SA. (1997). Betaine improves the PCR amplification of GC-rich DNA sequences. Nucleic Acids Res 25:3957-8.

Hong H, Lin L. (2010). Study on the fauna of the Scyphomedusae in the China Sea. J Jimei Univ (Nat Sci) 15:18-24.

Ki JS, Hwang DS, Shin K, Yoon WD, Lim D, Kang YS, Lee JS. (2008). Recent moon jelly (Aurelia sp. 1) blooms in Korean coastal waters suggest global expansion: Examples inferred from mitochondrial COI and nuclear ITS-5.8 S rDNA sequences. ICES J Mar Sci 65:443-52.

Ki JS, Hwang DS, Lee JS. (2010). Simultaneous detection of Aurelia and Chrysaora scyphozoan jellyfish on a DNA microarray. J Mar Biol Assoc UK 90:1111-17.

Laakmann S, Holst S. (2014). Emphasizing the diversity of North Sea hydromedusae by combined morphological and molecular methods. J Plankton Res 36:64-76.

Lu Z, Dai Q, Yan Y. (2003). Fishery biology of Cyanea nozakii resources in the waters of Dongshan Island. Chin J Appl Ecol 14:973-6.

Lucas CH, Graham WM, Widmer C. (2012). Jellyfish life histories: Role of polyps in forming and maintaining scyphomedusa populations. Adv Mar Biol 63:133-96.

Miranda LS, Collins AG, Marques AC. (2010). Molecules clarify a cnidarian life cycle-The "Hydrozoan" Microhydrula limopsicola is an early life stage of the Staurozoan Haliclystus antarcticus. PloS One, 5:10182.

Mori Y, Nagamine K, Tomita N, Notomi T. (2001) Detection of loopmediated isothermal amplification reaction by turbidity derived from magnesium pyrophosphate formation. Biochem Biochem Biophys Res Co 289:150-4.

Nagamine K, Hase T, Notomi T. (2002). Accelerated reaction by loopmediated isothermal amplification using loop primers. Mol Cell Probes 16:223-9.

Nagai S, Yamamoto K, Hata N, Itakura S. (2012). Study of DNA extraction methods for use in loop-mediated isothermal amplification detection of single resting cysts in the toxic dinoflagellates Alexandrium tamarense and A. catenella. Mar Genom 7:51-6.

Notomi T, Okayama H, Masubuchi H, Yonekawa T, Watanabe K, Amino N, Hase T. (2000). Loop-mediated isothermal amplification of DNA. Nucleic Acids Res 28:63-63.

Ortman BD, Bucklin A, Pagès F, Youngbluth M. (2010). DNA barcoding the medusozoa using mtCOI. Deep-Sea Res PT II 57:2148-56.

Picon-Camacho SM, Thompson WP, Blaylock RB, Lotz JM. (2013). Development of a rapid assay to detect the dinoflagellate Amyloodinium ocellatum using loop-mediated isothermal amplification (LAMP). Vet Parasitol 196:265-71.

Wang B, Li Y, Shen H, Li Y, Wang W, Sun M, Dong J. (2014). Quantity distribution of Cyanea nokazii in inshore waters of northern Liaodong Bay, Bohai Sea in 2005-2013. Mar Fish 36:146-54.

Woźniakowski G, Kozdruń W, Samorek-Salamonowicz E. (2012). Loopmediated isothermal amplification for the detection of goose circovirus. Virol J 9:1-11.

Xian W, Kang B, Liu R. (2005). Jellyfish blooms in the Yangtze Estuary. Science 307:41.

Zhang F, Shi Y, Jiang K, Song W, Ma C, Xu Z, Ma L. (2014). Rapid detection and quantification of Prorocentrum minimum by loopmediated isothermal amplification and real-time fluorescence quantitative PCR. J Appl Phycol 26:1379-88.

Zhang M, Jing HL, Zhang LF, Wang N, Wu SQ, Lin XM. (2013). A loopmediated isothermal amplification method for the detection of members of the genus Ranavirus. Arch Virol 158:2121-6.

Zhong X, Tang J, Liu P. (2003). A study on the relationship between Cyanea nozakii Kishinouye breaking out and ocean ecosystem. Modern Fish Infor 19:15-7 (in Chinese).

Zhou T, Huang M. (1956). Cyanea nozakii: A predator to commercial fishery species in Yellow and Bohai Sea. Biol Bull 6:9-12. (in Chinese). 